\title{
Simultaneously enhancing the strength, ductility and conductivity of copper matrix composites with graphene nanoribbons
}

\author{
By Ming Yang,$^{\dagger}$ Ling Weng,${ }^{\dagger}$ Hanxing Zhu, ${ }^{\S}$ Tongxiang Fan, ${ }^{\dagger *}$ and Di Zhang ${ }^{\dagger}$ \\ †Prof. Tongxiang Fan, Corresponding Author, Prof. Di Zhang, Dr. Ming Yang and Dr. Ling \\ Weng \\ State Key Laboratory of Metal Matrix Composites, Shanghai Jiaotong University \\ Shanghai, 200240, P.R. China \\ E-mail: (txfan@situ.edu.cn) \\ ${ }^{\S}$ Dr. Hanxing Zhu \\ School of Engineering, Cardiff University, Cardiff CF24 3AA, UK
}

\begin{abstract}
The incorporation of low-dimensional nanomaterials into 3D metal matrices are promising to translate their intriguing properties from nanoscale to the macroscopic world. However, the design of robust nanofillers and effective fabrication of such bulk composites remain challenging. Here we report a configuration design of nnanocarbon for reinforcing metals via unzipping carbon nanotubes (CNTs) into graphene nanoribbons (GNRs), which are novel quasi-1D carboneous nanomaterials combining elegantly the properties of graphene nanosheets and CNTs, to provide insight into the viability to retrieve good plasticity and conductivity that defy the boundaries of classical composites. We realize an optimal balance between elevated yield strength and impressively larger plastic deformation coupled with a simultaneous improving of electrical conductivity (216 MPa, $8.0 \%$ and $54.89 \mathrm{MS} \mathrm{m}^{-1}$, i.e. 1.55 folds, $130.4 \%$ and $105 \%$ of the matrix, respectively), by highlighting that the excellent intrinsic properties, strong interfacial bonding, optimized orientation control and especially the unique geometric factors of GNRs are conductive to transmitting stress from $\mathrm{Cu}$ matrix without sacrificing the ductility and electrical conductance. This work provides a new vista on the integration and interaction of noval low-dimensional nanofillers with bulk 3D metal matrices.
\end{abstract}




\section{Introduction}

The incorporation, integration and interaction of low-dimensional nanomaterials (from OD to 2D) with bulk 3D metal matrices have stimulated tremendous interest in condensed matter physics and material science, to explore and translate their intriguing properties from nanoscale to the macroscopic world. In particular, nanocarbon addition into metals in a typical form of 1D carbon nanotubes (CNTs) or 2D graphene nanosheets (GNSs) has an attractive prospect to take advantage of their extraordinary mechanical properties, conductive properties and size effects, with expectation to achieve advanced metal-based nanocomposites for power electronic devices, thermal management, mechanical and structural applications [1-3]. Although CNTs [4-8] and GNSs [9-19] have shown great potential for improving the strength, stiffness and thermostability of metal matrices, through cumbersome fabricating processes, the resultant enhancement efficiency is always much lower than expected. This may be attributed to the agglomeration and damage of nanocarbons during processing as well as their poor interfacial bonding and compatibility with matrices, delivering a disappointing load-bearing capacity in metal environments [1-3].

Notably, when serving as nanofillers, their size, dimension, geometry, distribution and orientation substantially affect the load-transfer strengthening ability and consequently the overall mechanical response of composites at the macroscale [15,20]. In general, stress transfer from matrix to the enhancer is traditionally modelled using well-established shear-lag theory. This theory states that load-transfer occurs via the shear stress generated at the interface between the metal matrix and the inclusions. Accordingly, the maximum stress in the nanofiller is related to the shear stress of the metal matrix, and there is an optimum aspect ratio which enables the failure of both the shear-strained matrix and the strong nanocarbon to occur at the 
same time [21]. Thus, for GNSs, their low aspect ratio (typically <5) cannot offer an adequate length to maximize the stress-bearing capacity in the strained composites. As to CNTreinforced composites, the exceptional strength of nested inner graphene walls in multi-walled CNTs (MWCNTs) can hardly be utilized due to the extremely weak inter-wall shear resistance, allowing only the defective outermost wall to carry the load [22,23]. On the other hand, emerging electronic devices, high-power facilities, aerospace, transportation, military and other technologies create constantly increasing multi-parameter demands for conductors, such as high levels of mechanical strain/stress, bending tolerance, electrical conductivity, thermal stability and so forth. Unfortunately, given the general correlation between fatigue limit and yielding strength in most man-made structural materials, especially in metal matrix composites (MMCs), a dramatic loss of ductility is frequently accompanied with the improvement of mechanical strength owing to strain localization and a lack of stable deformation [19,24]. In addition, a concomitant degradation of electrical or thermal transport performance, triggered by the lattice (e.g., solution atoms and dislocations) and interface dissipation of conducting mediums (i.e. electrons and phonons), is always observed when doping pure metals $[1,2]$. Carbon nanofillers have also shown great potential for improving the electrical performance of polymer matrices [25-27] and electrode materials [28], however, exploring the electrical properties of metal-nanocarbon bulks remains limited. It is therefore of critical importance to develop possible enhancer for reinforcing metals comprehensively.

Here we report a configuration design of nanocarbon for reinforcing metals via unzipping MWCNTs into graphene nanoribbons (GNRs), which are novel quasi-1D carboneous nanomaterials combining elegantly the properties of GNSs and CNTs, to provide insight into the viability to retrieve good plasticity and conductivity that defy the boundaries of classical MMCs. GNRs featuring high strength, flexibility, stretchability, stiffness and surface area, flat 
geometry, large aspect ratio ( $c a$. several hundred) together with appealing conductance are expected as ideal candidates for enhancing the overall performance of metals, and perhaps lead to novel macroscopic metal-nanocarbon compounds with unprecedented multifunctional properties[29,30]. Typical metallic functional material, pure copper, is specifically chosen in this work as a 3D host in order to investigate both the mechanical and electrical responses to GNR incorporation. Bulk copper matrix composites reinforced with individually embedded GNRs (designed as $\mathbf{C u / G N R s ~ h e r e a f t e r ) ~ a r e ~ f a b r i c a t e d ~ v i a ~ a ~ f a c i l e ~ a n d ~ s c a l a b l e ~ s o l u t i o n - b a s e d ~}$ hetero-aggregation method followed by rapid densification processes. We realize an optimal balance between elevated strength and impressively larger plastic deformation coupled with a simultaneous improving of electrical conductivity ( 1.55 folds, $130.4 \%$ and $105 \%$ of the matrix, respectively), by highlighting that the excellent intrinsic properties, unique geometric factors, strong interfacial bonding and optimized orientation control of GNRs are conducive to transmitting stress from $\mathrm{Cu}$ matrix without sacrificing the ductility and electrical conductance in the $\mathrm{Cu}-\mathrm{GNR}$ system.

\section{Experimental}

\subsection{Raw materials}

Raw MWCNTs (Showa Denko Group, Japan) employed in this study were fabricated by catalytic chemical vapor deposition method followed by high-temperature annealing $\left(>2800{ }^{\circ} \mathrm{C}\right)$. Raw CNTs are highly straight with an average diameter of $120 \mathrm{~nm}$ and a length of $\sim 6 \mu \mathrm{m}$ (Fig. S1). $99.9 \%$ purity $\mathrm{Cu}$ powders with spheric shape and a diameter ranging from $0.2 \mu \mathrm{m}$ to $2 \mu \mathrm{m}$ were fabricated by gas evaporation method and provided by Dingkai Technologies, Nanjing, China. Concentrated $\mathrm{H}_{3} \mathrm{PO}_{4}(85 \mathrm{wt} \%)$, concentrated $\mathrm{H}_{2} \mathrm{SO}_{4}(97 \mathrm{wt} \%)$, concentrated $\mathrm{HCl}(36 \mathrm{wt} \%), \mathrm{H}_{2} \mathrm{O}_{2}(30 \mathrm{wt} \%)$ and $\mathrm{KMnO}_{4}$ were of analytical grade and provided by Sinopharm Chemical Regent Co., LTD, China. 


\subsection{Preparation of $\mathrm{Cu} / \mathrm{GNR}$ hybrid powders}

Mass GNRs were synthesized from MWCNTs by a facile chemical unzipping method [31]. Briefly, $150 \mathrm{mg}$ of MWCNTs was suspended in $36 \mathrm{~mL}$ of concentrated $\mathrm{H}_{2} \mathrm{SO}_{4}$ by stirring the mixture for a period of $1 \mathrm{~h}$. Concentrated $\mathrm{H}_{3} \mathrm{PO}_{4}(4 \mathrm{~mL})$ was then added, and the mixture was allowed to stir another $15 \mathrm{~min}$ before the addition of $\mathrm{KMnO} 4(750 \mathrm{mg})$. The reaction mixture was then heated at $75^{\circ} \mathrm{C}$ for $2 \mathrm{~h}$, and then allowed to cool to room temperature. The product was poured onto $200 \mathrm{~mL}$ of ice containing $\mathrm{H}_{2} \mathrm{O}_{2}(5 \mathrm{~mL})$, followed by filtration through a $5 \mu \mathrm{m}$ PTFE membrane. The collected mud was washed once with $20 \% \mathrm{HCl}$, three times with ethanol, then dried in vacuum at $60{ }^{\circ} \mathrm{C}$ to obtain the final GNR product.

GNRs and $\mathrm{Cu}$ powders were firstly dispersed in ethanol solution for $2 \mathrm{~h}$ by sonicating and magnetic stirring, respectively. Then the GNR suspension $\left(0.1 \mathrm{~g} \mathrm{~L}^{-1}, \underline{\text { Fig. S2 }} \mathrm{a}\right)$ and the $\mathrm{Cu}$ slurry (10 $\mathrm{g} \mathrm{L}^{-1}$, Fig. S2b $)$ were carefully blended together at various mixing ratios from 0 to 3.0 vol\% GNRs and stirred for $30 \mathrm{~min}$, to ensure a uniform dispersion of individual GNRs (IGNRs). The mixed slurry were let stand until the supernatant turn from dark red to transparent, which inferred an entire transfer of the I-GNR suspension into the metal one. After carefully removing the clear supernatant, the sediment was collected and dried in vacuum at $60{ }^{\circ} \mathrm{C}$ for $24 \mathrm{~h}$. It is noteworthy that there are no free I-GNRs in the supernatant (Fig. S2c), therefore no re-agglomeration could occur during ethanol removal.

\subsection{SPS and hot-rolling}

Twenty grams of the collected $\mathrm{Cu} / \mathrm{GNR}$ hybrid powders (Fig. S2d) were pre-compacted in a graphite die. Subsequently, the powders were consolidated by spark plasma sintering at $600{ }^{\circ} \mathrm{C}$ for 5 min under a vacuum of $0.1 \mathrm{~Pa}$ with an applied pressure of $50 \mathrm{MPa}$. The as-sintered composites were $28 \mathrm{~mm}$ in diameter and $3.5 \mathrm{~mm}$ in thickness (Fig. S2e). Hot rolling at $800{ }^{\circ} \mathrm{C}$ by an $86 \%$ reduction in thickness was employed to manipulate GNR arrangement and obtain 
fully densified composites with a final thickness of about $0.5 \mathrm{~mm}$ (Fig. S2f). During each rolling cycle, specimens were annealed in muffle furnace at $800{ }^{\circ} \mathrm{C}$ for $5 \mathrm{~min}$ before rolling with a 5\% thickness reduction, and the total number of rolling cycles was 15 .

\subsection{Tensile, bending and electrical tests}

For uniaxial tensile tests, dog bone-shaped specimens of $10 \mathrm{~mm}$ gauge length, $2 \mathrm{~mm}$ width, and $0.33 \mathrm{~mm}$ thickness were cut from the as-fabricated plates by electro-discharging machining, with the tensile axis paralleling to the rolling direction. Tensile properties were measured at room temperature on a universal testing machine (Zwick/Roell Z020 system) with a strain rate of $5 \times 10^{-4} \mathrm{~s}^{-1}$. Bending tests with a three-point bending configuration were carried out on a Zwick/Roell Z100 system at a crosshead speed of $4 \mathrm{~mm} \mathrm{~min}^{-1}$. The electrical conductivities of the samples were measured by a standard two-probe method using a low-ohm meter (TH 2513/A, Tonghui Electronic, Changzhou, China). A constant current of 1 A was applied for the conductivity tests.

\subsection{Materials characterization}

The fracture topographies and microstructures of raw CNTs and bulk $\mathrm{Cu} / \mathrm{GNRs}$ were characterized using a field-emission scanning electron microscopy (SEM, S-4800, HITACHI). The grain boundaries (GBs) and GNR configuration in bulk $\mathrm{Cu} / \mathrm{GNRs}$ were observed after etching with a solution of $5 \mathrm{~g}$ of $\mathrm{FeCl}_{3}, 15 \mathrm{ml}$ of $\mathrm{HCl}$ and $85 \mathrm{ml}$

of $\mathrm{H}_{2} \mathrm{O}$. Energy dispersive spectrometer (EDS) and electron back-scattered diffraction (EBSD) characterizations were performed in a field emission SEM (NOVA NanoSEM 230, FEI) fitted with an AZTec HKL Max EDS and EBSD detector at an accelerating voltage of $20 \mathrm{kV}$. The scanning step size for EBSD was $0.3 \mu \mathrm{m}$. The resulting orientation distribution function figures, polar graphs, 
distributions of Schmid factor and grain-boundary misorientation were obtained from post-treatments of these orientation maps using the HKL Channel-5 software. A transmission electron microscopy (TEM) and high resolution TEM (JEM 2100F, JEOL) was used to obtain information on the nanostructure and interfaces of the samples, operating at $200 \mathrm{KV}$. TEM samples were prepared by standard polishing followed by ion milling (Gatan PIPS, Model 691, Oxford). Topographic imaging and height profile of GNRs were measured by tapping mode at room temperature using an atomic force microscopy (AFM) system (Multimode 8, Bruker). Samples were prepared by casting onto a clean $\mathrm{Si} / \mathrm{SiO}_{2}$ substrate.

The crystallographic structure was analyzed by X-ray diffraction (XRD, Ultima IV, Rigaku), using $\mathrm{Cu} \mathrm{Ka}(\lambda=1.5406 \AA)$ radiation operating at $35 \mathrm{kV}$ and $200 \mathrm{~mA}$. The data were collected for a $2 \theta$ angle ranging from $30^{\circ}$ to $100^{\circ}$ with a scan rate of $0.5^{\circ} \mathrm{min}^{-1}$ and a step size of $0.02^{\circ}$. The dislocation densities of the samples were determined by extrapolating the lattice parameters and micro-strain from the XRD profiles. X-ray photoelectron spectroscopy (XPS, AXIS UltraDLD, Kratos), Raman spectroscopy (LabRAM HR Evolution, HORIBA), Fourier transform infrared (FTIR, Nicolet 6700, ThermoFisher) and micro-FTIR (Nicolet iN10 MX, ThermoFisher) were utilized to analyze the surface chemistry and structural characteristics. In detail, XPS data were recorded with the following parameters: Al $\mathrm{K} \alpha=1486.6 \mathrm{eV}$, power $=150 \mathrm{~W}(\mathrm{HV}=15 \mathrm{kV}$ and $\mathrm{I}=10 \mathrm{~mA})$, the carbonaceous $\mathrm{C} 1 \mathrm{~s}$ line $(284.6 \mathrm{eV})$ was employed as the reference to calibrate the binding energies; Raman spectroscopies were collected using an excitation wavelength of $532 \mathrm{~nm}$ under a 200s acquisition time; FTIR spectra of CNTs and GNRs were obtained using $\mathrm{KBr}$ discs under transmission mode whereas micro-FTIR spectra of bulk $\mathrm{Cu} / \mathrm{GNRs}$ were achieved under reflection mode, with a scan range of $400-4000 \mathrm{~cm}^{-1}$ and signal averaging 64 scans at a resolution of $4 \mathrm{~cm}^{-1}$. Zeta potential 
measurements were conducted on a Malwen Zetasizer Nano S90 system. Before measurement, both $\mathrm{Cu}$ and GNR samples were dispersed in ethanol at a concentration of $0.1 \mathrm{~g} \mathrm{~L}^{-1}$ by sonicating for $30 \mathrm{~min}$. The data collection was repeated for at least five times and then averaged.

\section{Results and discussion}

\subsection{Fabrication of $\mathrm{Cu} / \mathrm{GNRs}$}

Fig. 1a depicts the schematic of the fabrication of $\mathrm{Cu} / \mathrm{GNRs}$, and details for the preparation process and microstructure evolution can be found in Fig. S2 and Table S1 of the Supporting Information. A wet-fusing assembly approach, namely the hetero-aggregation method [32,33], was employed to obtain homogenously mixed $\mathrm{Cu} / \mathrm{GNR}$ composite powders, which enabled quick assembly, clean interface and scalable preparation. Mass GNRs were firstly prepared by chemical unzipping of MWCNTs [31]. The detail of the unzipping mechanism is described elsewhere $[31,34,35]$. As illustrated by the TEM image (Fig. 1b) and AFM topography (Fig. 1c), the oxidative derived GNRs have a basal dimension of 2-6 $\mu \mathrm{m}$ in length and 50$300 \mathrm{~nm}$ in width, whilst the TEM imaging (Fig. S3), well-defined selected area electron diffraction (SAED) pattern (Fig. 1b inset) and a thickness of $\sim 1 \mathrm{~nm}$ (Fig. 1c inset) indicate that monolayer is achieved. GNRs are well-dispersed in solvents because they are enriched with negatively charged, hydrophilic moieties (carboxyl, hydroxyl and epoxy groups), as verified by the XPS profile (Fig. 1d), FTIR spectra (Fig. S4) and zeta potential measurement $(\zeta=-53 \mathrm{mV})$ [35]. Concurrently, $\mathrm{Cu}$ powders with an average diameter of $0.2-2.0 \mu \mathrm{m}$ have positive charge on the surface $(\zeta=+10 \mathrm{mV})$ when dispersed in ethanol solution. As a result, when these suspensions are co-blended, a large number of $\mathrm{Cu}$ particles are available to arrest, sandwich and anchor I-GNRs through electrostatic force adsorption. This interaction may lead to a co-deposition of $\mathrm{Cu}$ particles and GNRs at the bottom of the solutions due to the much 
higher density of $\mathrm{Cu}$ particles than ethanol. The $\mathrm{Cu} / \mathrm{GNR}$ deposit is facile to separate from the supernatant, giving rise to well-dispersed GNRs in the powder mixtures (Fig. 1e) [32,33].

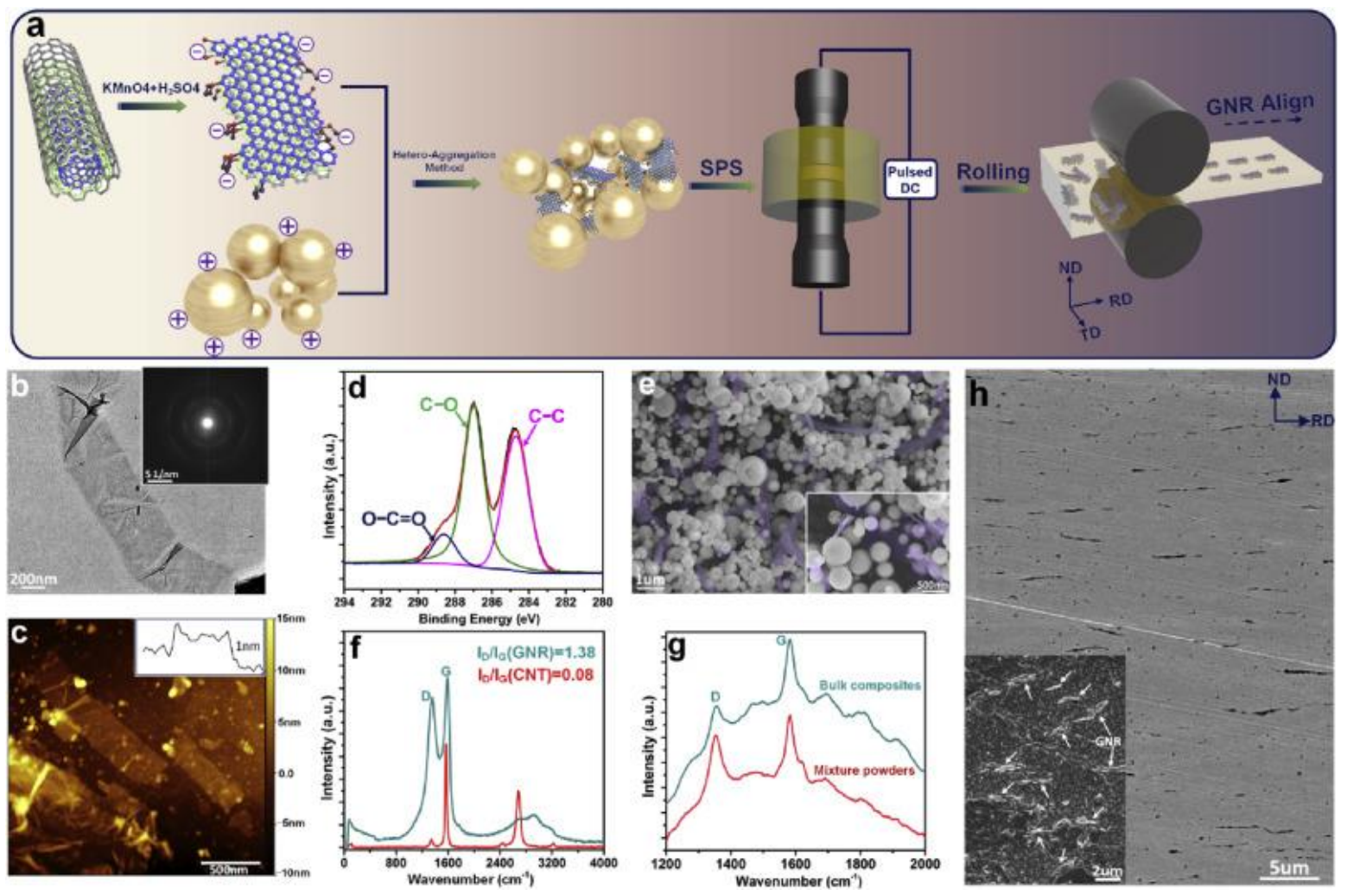

Fig. 1. (a) Schematic illustration for the production of $\mathrm{Cu} / \mathrm{GNR}$. RD, ND and TD represent the rolling, normal and transverse directions of the sample, respectively. (b) TEM image and c) AFM topograph of as-prepared GNRs, insets of (b) and (c) are the corresponding SAED pattern and line profile, respectively. (d) Deconvoluted XPS C1s spectrum of GNRs. (e) SEM images display the homogenously mixed $\mathrm{Cu} / \mathrm{GNR}$ hybrid powders. (f) Raman spectra of the pristine CNTs and chemical derived GNRs. (g) Raman spectra of bulk Cu/GNR composites. (h) SEM images prove well-embedded, uniformly-distributed and RD-aligned GNRs (inset is the etched surface).

The collected hybrid powders, consisting of numerous I-GNRs uniformly distributed within the $\mathrm{Cu}$ powder framework, were then consolidated and transformed into a fully dense, macroscopic 3D compound by spark plasma sintering (SPS) and hot rolling. Meanwhile, lengthwise rotation of GNRs occurred in the copper matrix during these heavy co-deformations, leading to a realignment of GNRs paralleling to the rolling direction, as manifested in Fig. $1 \mathrm{~h}$ and Fig. S5. Raman spectrographies (Fig. 1f-g) reveal a retrieved D to G peak intensity ratio 
$\left(\mathbf{I}_{\mathbf{D}} / \mathbf{I}_{\mathbf{G}}\right)$ of $\mathrm{Cu} / \mathrm{GNRs}$ relative to those of the free GNRs and $\mathrm{Cu} / \mathrm{GNR}$ powder mixtures, suggesting that GNR structure is largely restored because of the thermal recovery of $\mathrm{sp}^{2}$-bonded carbon lattice during the hot reduction processes (i.e. SPS and hot-rolling) [36,37].

\subsection{Unique mechanical and electrical properties of $\mathrm{Cu} / \mathrm{GNRs}$}

Typical tensile response of $\mathrm{Cu} / \mathrm{GNRs}$ and unfilled $\mathrm{Cu}$ are plotted in Fig. 2a. It is clear that a remarkable improvement of yield strength $(0.32-1.27$ folds greater than that of the undoped $\mathrm{Cu}$ ) is achieved by adding a $0.5-3.0$ vol\% of GNRs. Interestingly, besides of greatly strengthening the matrix material, a simultaneous enhancement of ductility in terms of uniform deformation and strain tolerance is also realized in our $\mathrm{Cu} / \mathrm{GNR}$ compounds. Specifically, the stress-strain curve of the monolithic $\mathrm{Cu}$ exhibits an initial hardening followed by quick saturation of the flow stress and an ensuing premature failure. However, with a 1.0 vol\% inclusion of GNRs, the strain-to-failure increases from $6.1 \%$ to $8.0 \%$ while the uniform elongation raises from $4.6 \%$ to $6.4 \%(\sim 30 \%$ and $\sim 39 \%$ enhancement over the $\mathrm{Cu}$ matrix,

respectively). The strain-hardening rate, defined as $\Theta=\frac{1}{\sigma}\left[\frac{\partial \sigma}{\partial \varepsilon}\right]_{i}$, is derived to clarify the origin of the improved ductility, where $\sigma$ and $\varepsilon$ are true stress and true strain respectively. The strain-hardening responses, i.e., the variation of normalized $\Theta$ with true strain (Fig. 2b) or true stress (Fig. 2b inset), reveal that $\mathrm{Cu} / \mathrm{GNRs}$ have a comparable $\Theta$ in the early deformation stage yet a more extended positive strain-hardening (i.e., a more durable steady strain ability without pronounced strain localization $[38,39]$ ) compared to that of pure $\mathrm{Cu}$. Moreover, $\mathrm{Cu} / \mathrm{GNRs}$ exhibit increased flexural strength (Fig. S6) as well as superb flexibility and deformability even through a $180^{\circ}$ bending test (Fig. 2c), which confirms a strength-toughness combination [40]. 

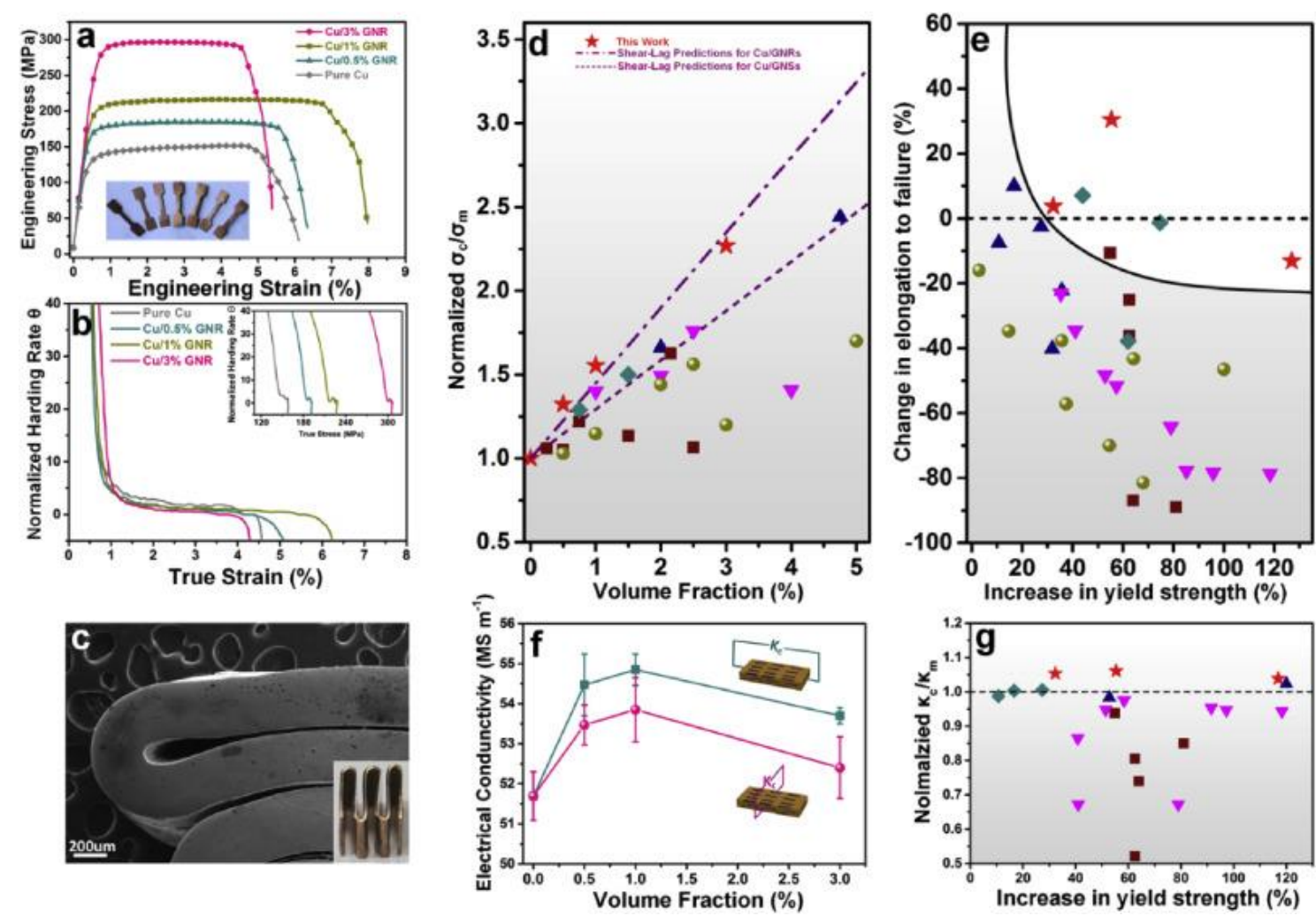

Fig. 2. Mechanical and electrical properties of the present $\mathrm{Cu} / \mathrm{GNRs}$ and unreinforced $\mathrm{Cu}$ : (a) Tensile engineering stress-strain curves, inset exhibits the dog-bone appearance of tensile specimens. (b) Plots of strain-hardening rate $\Theta$ versus true strain and true stress (inset) derived from the corresponding true stress-strain curves. (c) SEM image and photograph (inset) of a $180^{\circ}$ bending sample indicate high deformability and toughness of the composites. (d) Normalized $\sigma_{\mathrm{c}} / \sigma_{\mathrm{m}}$ versus reinforcement fraction of $\mathrm{Cu} / \mathrm{GNRs}$ and $\mathrm{Cu} / \mathrm{GNSs}$. The values are compared with the corresponding predictions by shear-lag model. (e) Change in elongation vs. strength increment of the present $\mathrm{Cu} / \mathrm{GNRs}$ compared to previously reported $\mathrm{Cu} / \mathrm{GNSs}$. (f) Electrical conductivities measured along the RD and TD of the samples. (g) Normalized conductance versus strength increment of $\mathrm{Cu} / \mathrm{GNRs}$ and $\mathrm{Cu} / \mathrm{GNSs}$. Note that the literature data are for $\mathrm{Cu} / \mathrm{GNSs}$ fabricated by various kinds of methods, including molecular level mixing (pink down triangles [9-11]), flake powder metallurgy (green diamonds [12,13]), mechanical milling (brown circles[14-16]), wet mixing (purple squares [17,18]), and in-situ grown (blue up triangles [19]). Our bulk $\mathrm{Cu} / \mathrm{GNRs}$ with a balance of enhanced strength, ductility and conductance (shown as red stars) clearly stand out and beyond the known trend for the normal trade-off of strength-ductility and strengthconductivity.

Since GNSs have frequently exhibited better capacity for strengthening composites than other commonly used reinforcements (e.g., 1D nanotubes, ceramic particles and short-fibers) [3,1113], the strengthening efficiency of GNRs can be compared simply to those of Cu-based 
composites reinforced by GNSs (denoted as $\mathbf{C u} / \mathbf{G N S s}$ ) to isolate the effect of geometrical aspect ratio herein. As summarized in Fig. 2d, the values of yield strength ratio of composite to matrix $(\sigma \mathrm{c} / \sigma \mathrm{m})$ are in well consistent with the corresponding theoretical predictions from the aforementioned shear-lag model $[2,15]$ :

$$
\begin{array}{ll}
\sigma_{c}=\sigma_{f} V_{f}\left(1-\frac{l_{c}}{2 l}\right)+\sigma_{m}\left(1-V_{f}\right) & \text { for } \quad l>l_{c} \\
\sigma_{c}=\sigma_{f} V_{f}\left(\frac{l_{c}}{2 l}\right)+\sigma_{m}\left(1-V_{f}\right) & \text { for } \quad l<l_{c}
\end{array}
$$

where $\sigma f, \mathrm{Vf}, \mathrm{l}, \mathrm{w}$ and $\mathrm{t}$ are the strength, volume fraction, length, width and thickness of the nanofiller, $\tau \mathrm{m}$ is the shear strength of the matrix $(\sim 0.5 \sigma \mathrm{m}, \sigma \mathrm{m}$ is the tensile yield strength of the matrix), and $l_{c}=\frac{\sigma_{f} \times w \times t \times l}{\tau_{m} \times(w+t) \times l}$ represents the critical length of reinforcement to carry a maximum stress at its midpoint (see Table 1). Besides, $\mathrm{Cu}$ /GNRs stand out, above and beyond the $\sigma \mathrm{c} / \sigma \mathrm{m}$ ranges of $\mathrm{Cu} / \mathrm{GNSs}$, verifying that GNRs are even more effective than GNSs, and thus most common additives for transferring load and strengthening MMCs. The superior capacity of GNRs in improving the strength-ductility combination can be further evaluated by comparison to those obtained in $\mathrm{Cu} / \mathrm{GNSs}$ (Fig. 2e) and other types of reinforcements (Table S2). Our Cu/GNR composites clearly stand out and beyond the known trend for the normal trade-off of strength-ductility of $\mathrm{Cu} / \mathrm{GNSs}$ fabricated through various methods (Fig. 2e). Moreover, $\mathrm{Cu} / \mathrm{GNRs}$ demonstrate a margin and anisotropic gain of intrinsical conductivity relative to neat $\mathrm{Cu}$ (Fig. 2f). The electrical conductivities of $\mathrm{Cu} / \mathrm{GNRs}$ are $4.1 \% .5 .0 \%$ and $2.7 \%$ higher than the matrix with a GNR additive of $0.5 \mathrm{vol} \%, 1.0 \mathrm{vol} \%$ and $3.0 \mathrm{vol} \%$, respectively. By comparing the strength and electrical conductivity of our $\mathrm{Cu} / \mathrm{GNR}$ samples with those of previously reported $\mathrm{Cu} / \mathrm{GNSs}$ (Fig. $2 \mathrm{~g}$ and Table $\mathrm{S} 2$ ), it can be seen that $\mathrm{Cu} / \mathrm{GNRs}$ also outperform most of MMCs in terms of evading the strength-conductivity trade-off. 
Table 1. Theoretical prediction of yield strength-volume fraction relationships of $\mathrm{Cu} / \mathrm{GNRs}$ and $\mathrm{Cu} / \mathrm{GNSs}$ by the shear-lag model.

$\begin{array}{lllllllc} & \text { of }(\mathbf{G p a}) & \boldsymbol{L}(\mathbf{u m}) & \boldsymbol{W}(\mathbf{u m}) & \boldsymbol{t}(\mathbf{n m}) & \boldsymbol{l}_{\boldsymbol{c}}[\mathbf{u m}] & \tau \mathrm{\tau m}[\mathrm{Mpa}] & \sigma \mathrm{c} / \sigma \mathrm{m} \\ \mathbf{C u} / \mathbf{G N R s} & 10 & 6 & 0.2 & 5 & 1.084 & 45 & 1+44.9 \mathrm{VGNR} \\ \mathbf{C u} / \text { GNSs } & 10 & 0.6 & 0.5 & 5 & 1.1 & 45 & 1+29.3 \mathrm{VGNS}\end{array}$

\subsection{Strengthening mechanism}

Three key factors substantially determining the elegant combination of enhanced strength, extraordinary ductility and robust conductivity in the developed $\mathrm{Cu} / \mathrm{GNR}$ system are especially identified: (i) The intrinsic characteristics of GNRs (i.e., planar and quasi-1D geometry, considerable length, high strength and flexibility) render the three-dimensional I-GNR arrays as not only the barrier to dislocation motion but also the dislocation absorber for preventing dislocation pile-up [11]. This drastically alter the behaviour of dislocations at the metalgraphene interfaces in terms of dislocation initiation, propagation, motion and annihilation, leading to a good match of enhanced strength and ductility (work-hardening capability) by increasing resistance to dislocation glide and limiting stress/strain localization $[12,41]$.

(ii) The spatial geometry of the GNR network (i.e., GNR's homogeneous dispersion, crossgranular distribution coupling with their unidirectional arrangement in alignment to the loading axis), as demonstrated by SEM (Fig. 3) and TEM (Fig. 4a) images, are propitious to fully exert the electronic transport and load-bearing of GNRs along their longitudinal direction, as well as helping to generate and store dislocations without initiating cracks localized at GBs [42]. 

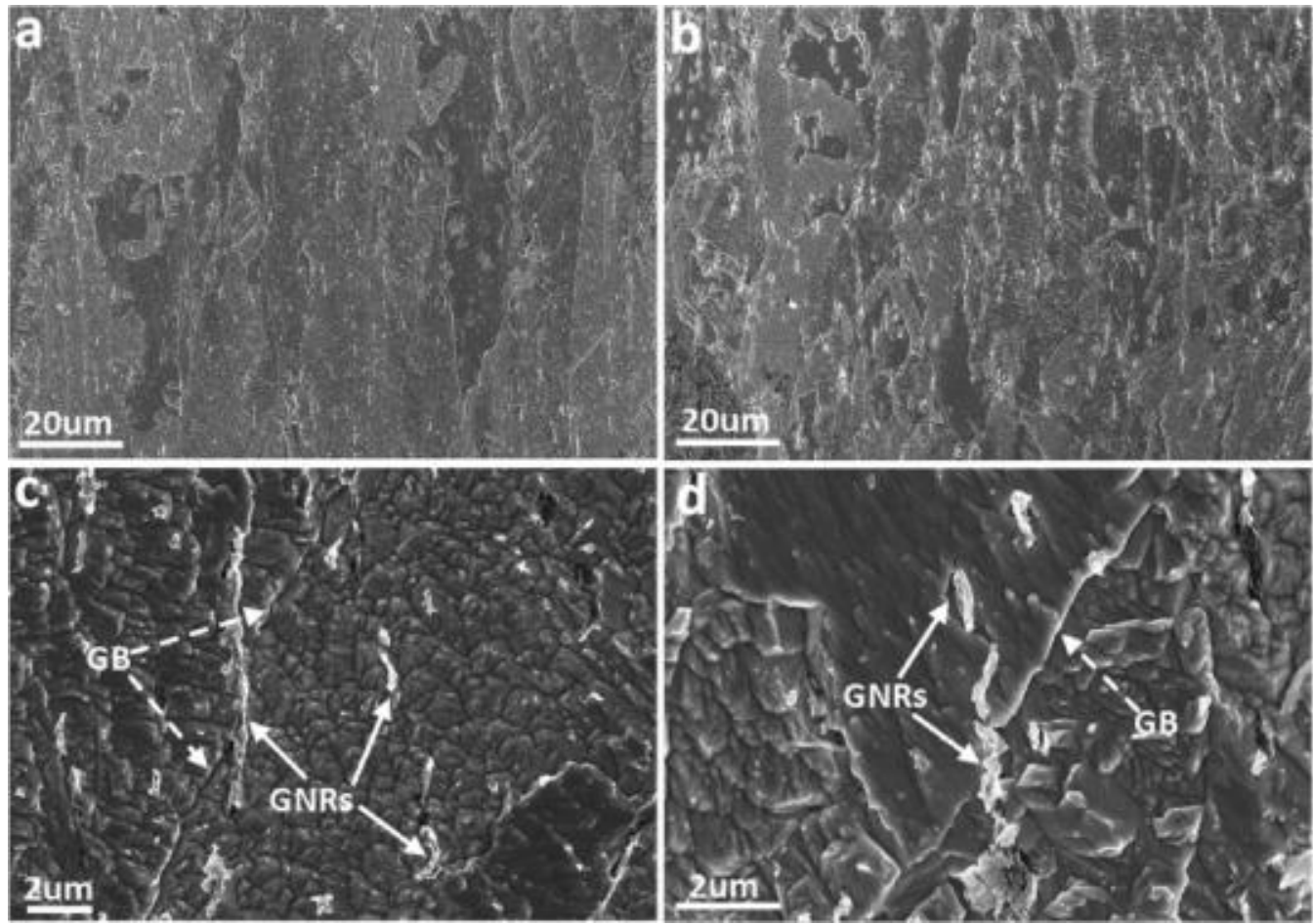

Fig. 3. (a-b) SEM images show the grain size of pure $\mathrm{Cu}$ and $\mathrm{Cu} / \mathrm{GNRs}$, respectively. The samples are etched with a solution of $5 \mathrm{~g}$ of $\mathrm{FeCl}_{3}, 15 \mathrm{ml}$ of $\mathrm{HCl}$ and $85 \mathrm{ml}$ of $\mathrm{H}_{2} \mathrm{O}$. (c-d) SEM images display the cross-granular distribution of I-GNRs. Full recrystallization and grain growth are detected in all the specimens during hot-rolling at $800{ }^{\circ} \mathrm{C}(0.74$ melting point of $\mathrm{Cu}$ ), which avoid GNR stacking at GBs of the matrix.
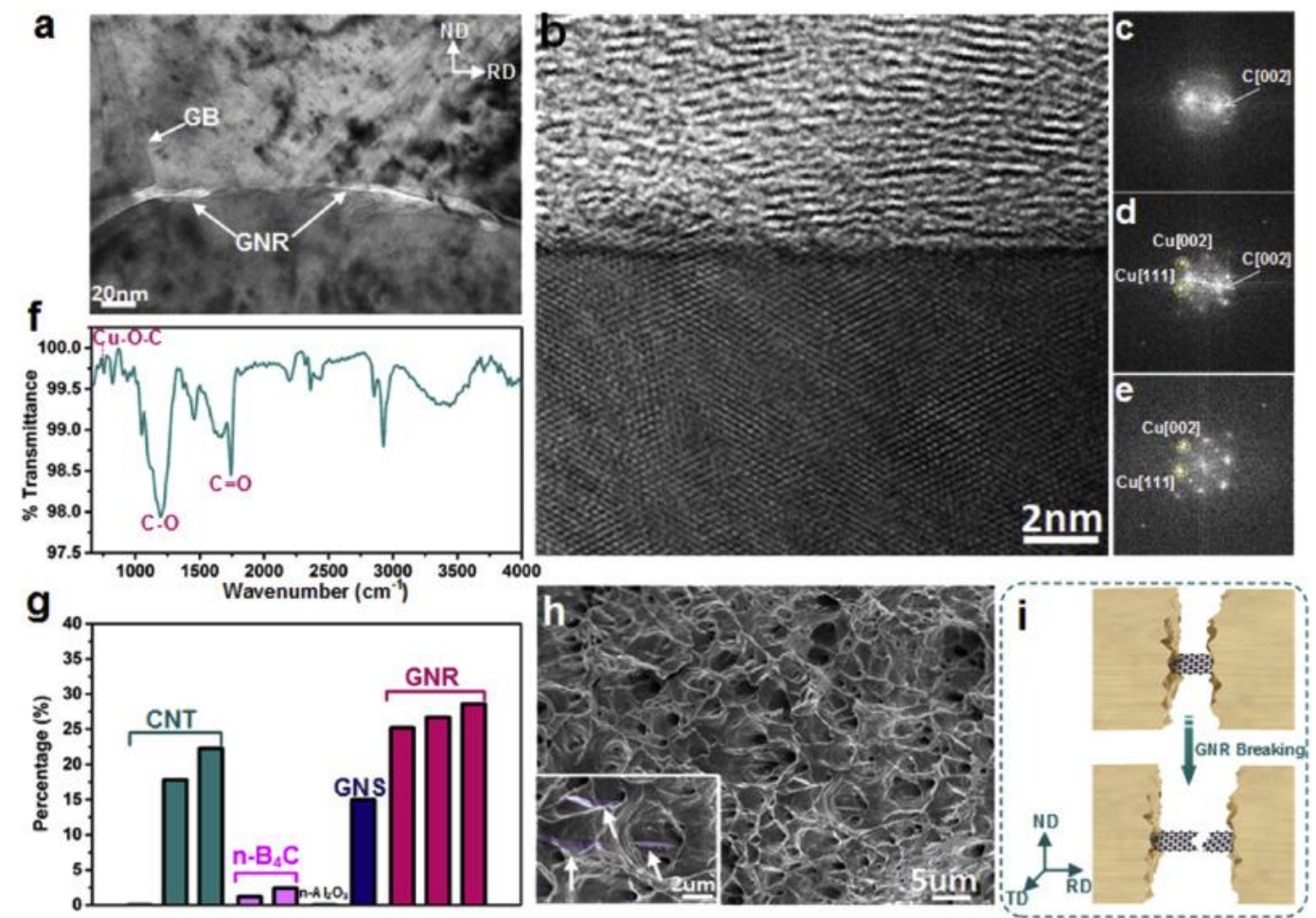

Fig. 4. (a) TEM and (b) HRTEM images show the GNR configuration and compact $\mathrm{Cu} / \mathrm{GNR}$ interface. (c-e) FFT patterns corresponding to the lattices of GNRs, $\mathrm{Cu} / \mathrm{GNR}$ interface and $\mathrm{Cu}$ 
shown in (b), respectively. Atomic-level intimate interface is indicated. (f) FTIR spectra of bulk Cu/GNR composites. (g) The contribution of load-transfer strengthening to the overall tensile strength. The proportion of GNRs are compared to those of some common nanofillers like CNTs [6-8], nano- $\mathrm{B}_{4} \mathrm{C}$ [46,47], nano- $\mathrm{Al}_{2} \mathrm{O}_{3}$ [48], and GNSs [49]. (h) SEM fractographs of $\mathrm{Cu} / \mathrm{GNRs}$ display ductile features, arrows indicate the pull-out of broken GNRs. (i) Schematic illustration showing frictional pull-out bridging and fracture process of a single GNR embedded in $\mathrm{Cu}$ matrix, effective load-sharing is implied.

(iii) An intimate interface between GNR and the matrix based upon a strong mechanical interlock effect, which is originated from the hot-consolidation processes and critically dictates interfacial shearing, compatible plastic strain, void nucleation, crack generation and electrical resistance, is essential for the co-existence of high load-transfer efficiency, enhanced strain tolerance and robust conductive transport in the composites [43]. This is supported by the high resolution TEM (HRTEM) imaging (Fig. 4b) and fast Fourier transformation (FFT) patterns (Fig. 4c-e), which show crystalline GNRs and a conformal interface. Moreover, the origin of entire wetting and enhanced bonding between GNR and metal can be explained by the existence of native oxygen on GNR surface. The formation of oxygen-mediated $\mathrm{Cu}-\mathrm{O}-\mathrm{C}$ bonding, which is collaborated by the FTIR spectrum (Fig. 4f) [44], may significantly improve the interfacial adhesion energy (as high as $164 \mathrm{~J} \mathrm{~m}^{-2}$ ) by strong covalent bonding $[11,45]$.

We first discuss the origin of the elevated strength as a consequence of load-transfer effect, geometrically necessary dislocation (GND) strengthening, and Orowan strengthening. In detail, GNDs, arising from the critical mismatch of coefficient of thermal expansions (CTEs) and elastic moduli between GNRs and the copper matrix, effectively increase the flow stress upon an applied strain. GNRs also effectively impede dislocation slipping and gliding, which jointly increases the strength of metal matrix [10-14,41]. Ex-situ TEM confirm a build-up of multiple dislocations at the $\mathrm{Cu} / \mathrm{GNR}$ interface (Fig. 5). According to the conventional Hall-Petch strengthening mechanism, dislocations pile up at the interface and eventually propagate through the interface when a critical shear stress is applied. The critical event in the case of our 
metal-nanoribbon system would be the activation of complex slip systems at high stresses and the pinned dislocations escaping through the free surfaces, because shearing through the stiff graphene layers is extremely difficult [41]. This GNR-dislocation interaction can be explained using the Orowan looping system, i.e., the Orowan strengthening mechanism. It is noteworthy that predominantly homogenous coarse-grained microstructures are found for both the pure $\mathrm{Cu}$ and $\mathrm{Cu} / \mathrm{GNRs}$ owing to obvious grain growth during hot-rolling (Fig. 3a-b), hence GB strengthening is negligible here for the great gain of mechanical strength.
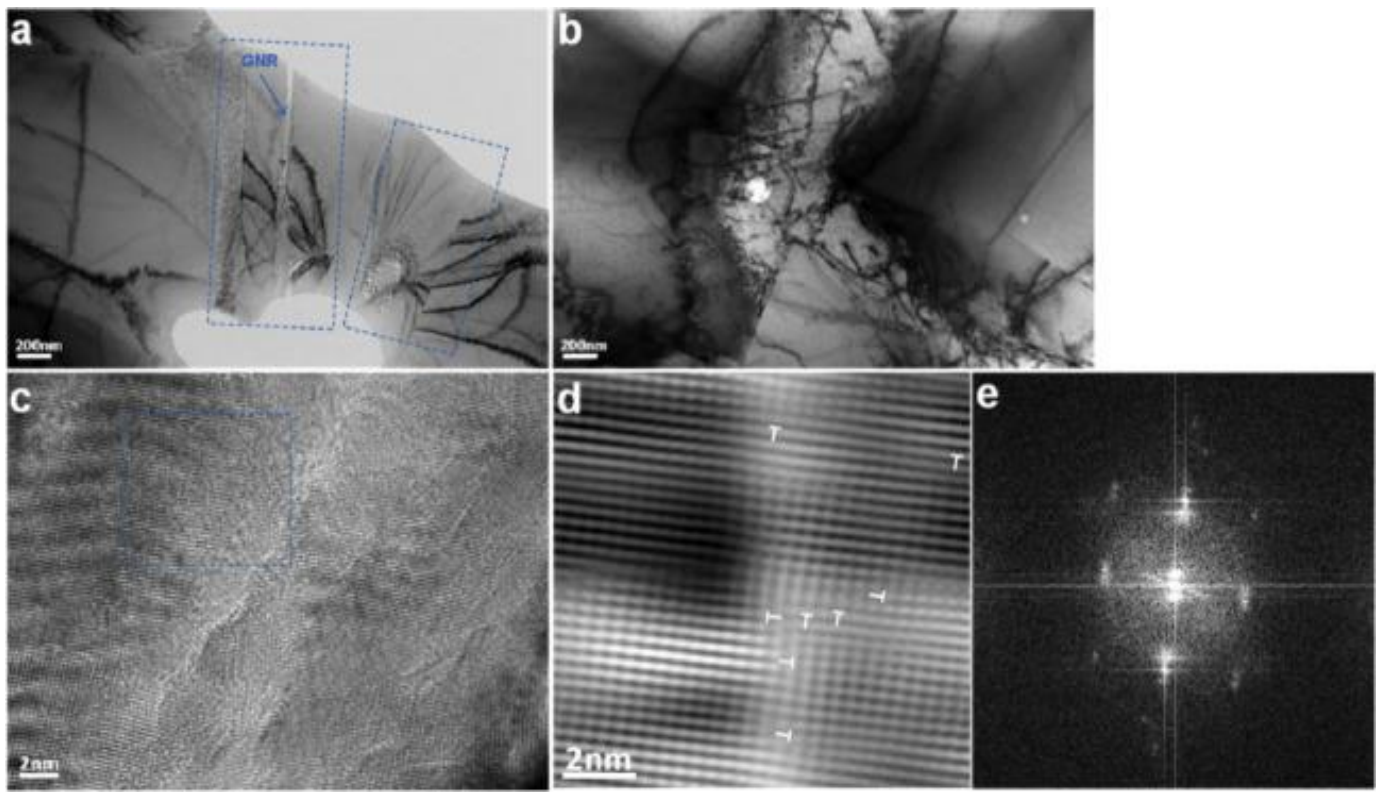

Fig. 5. (a-b) The configuration of dislocations in $\mathrm{Cu} / \mathrm{GNRs}$ after tensile deformation. Pileup and accumulation of dislocation groups around the $\mathrm{Cu} / \mathrm{GNR}$ interfaces and GBs are indicated. (c) HRTEM image reveals good bonding conditions between $\mathrm{Cu}$ matrix and GNR. (d-e) The corresponding inverse FFT figure and FFT pattern of the selected region in (c), respectively. Dislocations are marked by "T".

We further calculate the contribution of different strengthening factors as follows (see Table 2 for detailed results):

(i) Orowan strengthening mechanism (Eq. (3)) [14,48]:

$$
\sigma_{\text {Orowan }}=\frac{0.4 M G b}{\pi \lambda(1-v)^{1 / 2}} \ln \left(\frac{\pi \gamma_{S}}{4 b}\right)
$$


where Taylor factor $\mathrm{M}=3.06$, shear modulus $\mathrm{G}=42.1 \mathrm{Gpa}$, Poisson's ratio $v=0.355$, Burgers vector $b=0.256 \mathrm{~nm}$, effective reinforcement particle diameter $\gamma_{S}=\sqrt[3]{\frac{3 w t l}{4 \pi}}$, and effective planar inter-particle spacing $\lambda=\gamma_{S}\left(\sqrt{\frac{\pi}{2 V}}-1\right)$.

(ii) The geometrically necessary dislocation strengthening (Eq. (4)) [46,47,49]:

$$
\Delta \sigma_{G N D}=\alpha G b \sqrt{\frac{8 V_{f} \varepsilon_{y}}{b \gamma_{S}}+\frac{12 V_{f} \Delta C T E \Delta T}{b\left(1-V_{f}\right) \gamma_{S}}}
$$

where $\alpha$ the constant that is equal to $1.25, \varepsilon_{\mathrm{y}}$ is the yielding strain $(0.2 \%), \Delta \mathrm{CTE}$ is the CTE mismatch between $\mathrm{GNR}$ and $\mathrm{Cu}$, and $\Delta \mathrm{T}$ is the maximum temperature change during thermomechanical processing.

(iii) Load-transfer strengthening mechanism (Eq. (5)) [46]:

$$
\Delta \sigma_{L . T .}=\sigma_{C}-\Delta \sigma_{\text {Orowan }}-\Delta \sigma_{G N D}-\sigma_{m}
$$

Table 2. Contribution of different strengthening components for $\mathrm{Cu} / \mathrm{GNRs}$.

\begin{tabular}{lllll}
$\begin{array}{c}\text { Reinforcement fraction } \\
\text { (vol.\%) }\end{array}$ & $\begin{array}{c}\text { Orowan } \\
\text { strengthening (MPa) }\end{array}$ & $\begin{array}{c}\text { GND strengthening } \\
\text { (MPa) }\end{array}$ & $\begin{array}{c}\text { Load-transfer } \\
\text { strengthening (MPa) }\end{array}$ & $\begin{array}{c}\text { Composite } \\
\text { strength (MPa) }\end{array}$ \\
\hline 0.5 & 16.2 & 31.5 & 46.3 & 184 \\
1.0 & 23.5 & 44.8 & 57.7 & 216 \\
3.0 & 43.5 & 77.2 & 84.3 & 295 \\
\hline
\end{tabular}

Load-transfer strengthening accounts for a relatively large proportion in contributing to the overall strength increment of $\mathrm{Cu} / \mathrm{GNRs}$, as compared to those of other common MMCs (Fig. 4g). This preeminent load-transfer efficiency is evidenced by the observed breaking and stretching of I-GNRs at the fracture surface (Fig. 4h). The fractographs also display coarse dimples that are elongated in the loading direction, which further reflects the existence of plastic deformation and considerable toughness. As illustrated by the schematic showing 
of Fig. 4i, I-GNRs are supposed to break to failure without detaching from the softer and more compliant $\mathrm{Cu}$ matrix, rather than sliding and pulling-out like CNTs [4] and GNSs [20,50]. As expected, the strong interfacial adhesion and the intrinsic and extrinsic geometrical factors of GNRs may favor enhanced debonding length between matrix and GNRs and larger tensile displacements of the bridging ligaments. This unambiguously promotes a higher dissipation of fracture energy for toughening alongside the entire length of GNRs through interfacial shear stress, and hence a full achievement of the intrinsical strength of I-GNRs in response to loading.

\subsection{Toughening mechanism}

We next explain in more detail the exceptional improvement of ductility in the composite macrostructures. The transition from a pronounced strain-hardening regime to a steady flowstress regime (see Fig. 2a-b) may indicate that both the multiplication and annihilation of dislocations are operating simultaneously in the composites, and the overall deformation behavior is governed by the competition of the two processes $[12,42]$. The incorporation of evenly distributed GNRs will introduce rigid interfacial areas into the grain interior, which not only provide source sites for dislocation initiation but also serve as high-capacity sinks for pinning down and thereby accumulating dislocations [51]. Consequently, a prolonged dynamic balance between dislocation multiplication and annihilation occurs at the $\mathrm{Cu} / \mathrm{GNR}$ interfaces during deformation, leading to a more sustained uniform strain while maintaining a high level of strength [52]. The dislocation pinning and accumulation are justified by TEM (Fig. 5a-b) and HRTEM imaging (Fig. 5c-e), coupling with dislocation density change derived from the ex-situXRD patterns before and after tensile tests (Fig. 6a-b). The dislocation densities of bulk samples before and after the tensile tests are calculated by the following equation (Eq. (6)) [38]: 


$$
\rho=\frac{2 \sqrt{3}<\varepsilon^{2}>^{1 / 2}}{d_{X R D} b}
$$

where $\mathrm{dXRD}$ is crystallite diameter, $\varepsilon$ is microstrain, $b$ is the Burgers vector $(0.256 \mathrm{~nm}$ for $\mathrm{Cu})$. The values of $\mathrm{dXRD}$ and $\varepsilon$ are derived from the XRD peak broadening using the WilliamsonHall (W-H) method (Fig. 6c-d) [16].
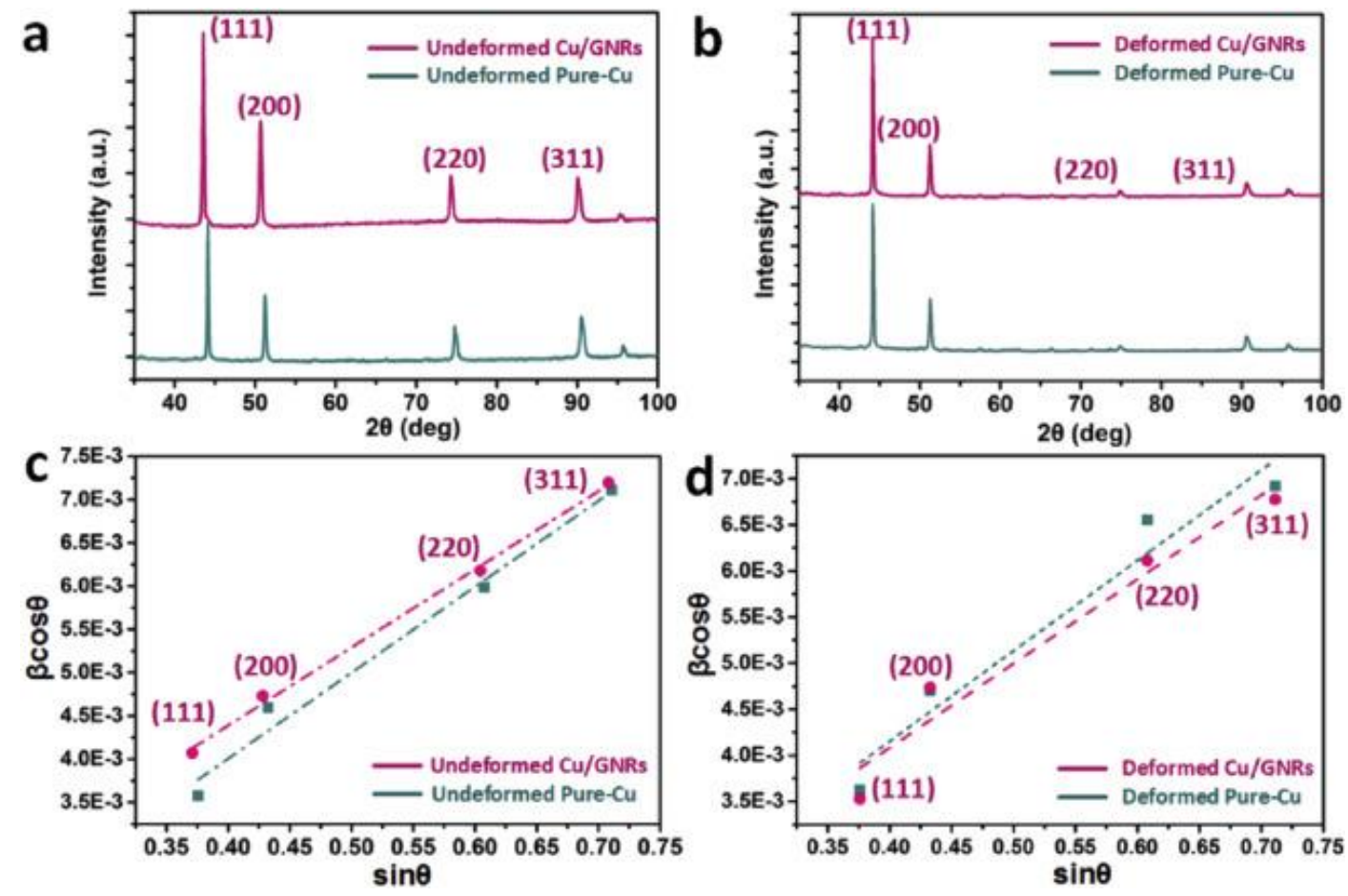

Fig. 6. XRD patterns of $\mathrm{Cu} / 1 \% \mathrm{GNR}$ and pure-Cu: (a) before and (b) after tensile deformation. (c-d) The Williamson-Hall plots in correspondence to (a) and (b), respectively.

It is found that there is a more pronounced increase of dislocation density in $\mathrm{Cu} / \mathrm{GNRs}$ (from $1.82 \times 10^{14}$ to $3.3 \times 10^{14} \mathrm{~m}^{-2}$ ) than that in neat $\mathrm{Cu}\left(\right.$ from $1.56 \times 10^{14}$ to $2.07 \times 10^{14} \mathrm{~m}^{-2}$ ) after deformation (Fig. 7a), suggesting that dislocation build-up might contribute to the sustained strain-hardening in the $\mathrm{Cu} / \mathrm{GNR}$ compounds (Fig. 7a inset). Note that the undoped $\mathrm{Cu}$ possesses a relatively low elongation $(\sim 6 \%)$, which may be ascribed to the pre-existing of micro-strains and a high level of matrix hardening. The hot-deformed grains after severe dynamic recovery and recrystallization allow limited lattice dislocation storage inside the 
grains, predetermining a premature strain localization and a less sustained strain-hardening ability [53].

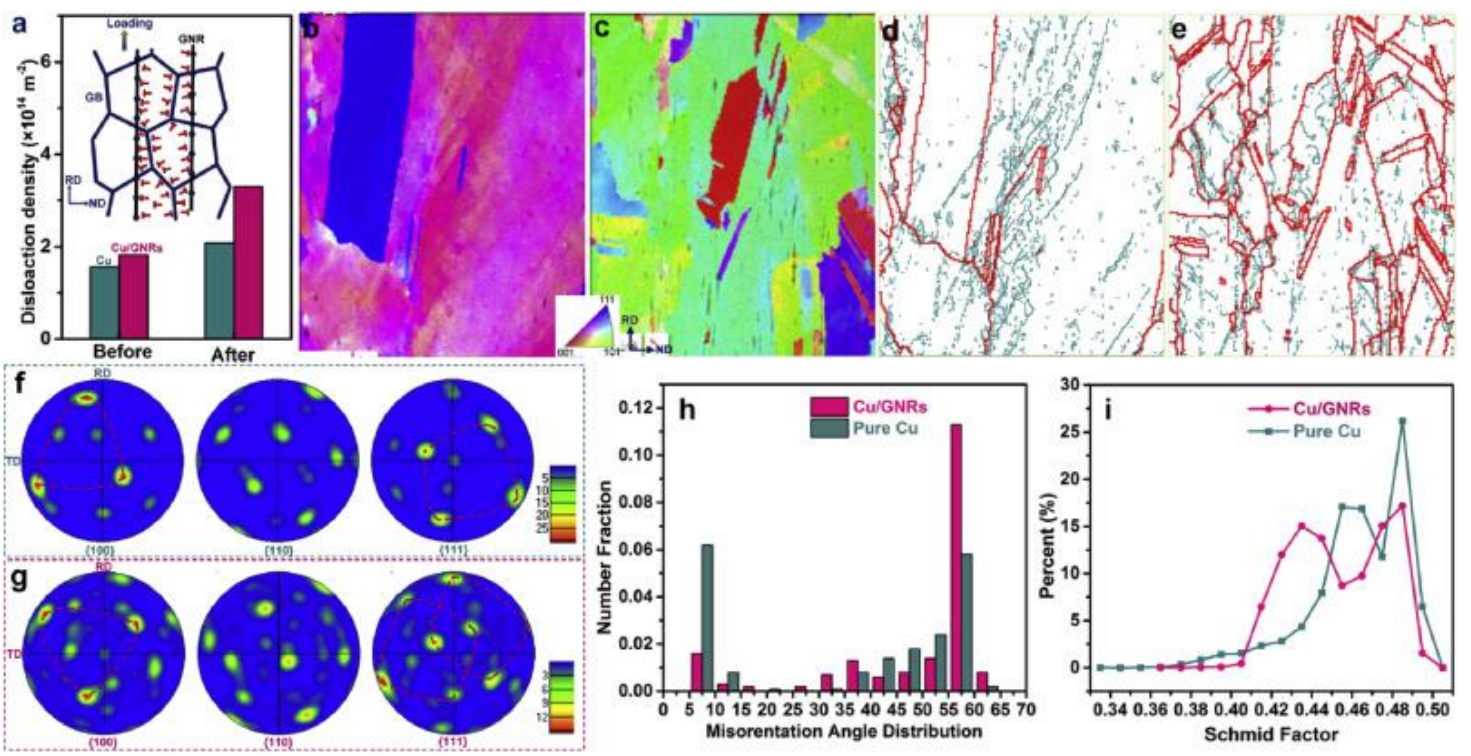

Fig. 7. (a) Comparison of the dislocation density of pure $\mathrm{Cu}$ and $\mathrm{Cu} / \mathrm{GNRs}$ before and after tensile deformation, inset is the schematic illustration of dislocation accumulation around GNRs. (b-c) EBSD micrographs of unreinforced $\mathrm{Cu}$ and $\mathrm{Cu} / \mathrm{GNRs}$, respectively. (d-e) GB misorientation distribution maps in correspondence to $(b-c)$, where red lines represent HAGBs $\left(>15^{\circ}\right)$ and green lines label as LAGBs $\left(2^{\circ}-15^{\circ}\right)$. (f-g) EBSD-generated $\{100\},\{110\}$ and $\{111\}$ polar graphs depict the textures derived from (b) and (c), respectively. (h) Distribution of GB misorientation angles derived from (d-e), a obviously larger proportion of HAGBs is detected in $\mathrm{Cu} / \mathrm{GNRs}$ than that in unfilled $\mathrm{Cu}$. (i) Distribution of Schmid factors in the RD in accordance with $(b-c)$.

On the other hand, at the yield point, the deforming grains tend to slip along the weakest planes, but the strong nanobelts might hinder further movement along those planes. Since the contact area of the nanoribbons is very large, this blockade would effectively prevent a localized deformation along weaker atomic planes and would enable the activation of sliding along other atomic planes, thereby promoting the ductility of $\mathrm{Cu} / \mathrm{GNRs}$ by increasing homogeneity in dislocation slip behavior [54]. Besides, the flatness, straightness, long and narrow shape of IGNRs are propitious to avoiding large-area wrinkling while promoting a cross-grained 
distribution of GNRs instead of residing at GBs like GNSs [14,15,37]. This substantially alleviates the propensity for intergranular fracture and thus ensures the total elongation before failure, because nanocarbon aggregation at GBs may induce large stress concentrations and make the weaker GBs preferential sites of interfacial decohesion and microcrack generation[43].

The responsible toughening mechanism is further correlated with the orientation and misorientation angle of matrix grains. The introduction of GNRs may principally restrict and inhibit the rotation, dynamic recovery and recrystallization of grains during hot-rolling, endowing $\mathrm{Cu} / \mathrm{GNRs}$ with distinct deformation texture and GB misorientation distributions from those of their monolithic part. As disclosed by the EBSD micrographs (Fig. 7b-c) and the associated polar graphs (Fig. 7d-e) and orientation distribution function figures (Fig. S7), there is a clear dominance of a typical rolling texture $(<111>/ / \mathrm{RD})$ in the unfilled $\mathrm{Cu}$ whereas GNR incorporation significantly weaken the <111> fiber component. It is known that the <111> tensile direction is a hard orientation for face-centered-cubic $\mathrm{Cu}$ with classical $\{111\}<110>$ slip systems [55]. Therefore, a lower value of Schmid factor is calculated for the Cu/GNR composites than that for the monolithic $\mathrm{Cu}$, as displayed in Fig. 7f, which is favorable for dislocation slipping and plastic deformation according to the Schmid law [38,39]. Quantitative EBSD analysis was also used to obtain information on the distributions of misorientation angle $(\theta)$ of neighboring grains. As depicted in Fig. $7 \mathrm{~g}-\mathrm{i}$, a markedly larger proportion $(90.2 \%)$ of high angle GBs $\left(\right.$ HAGBs, $\theta \geq 15^{\circ}$ ) and $\sum 3$ twin boundaries $\left(\mathbf{T B s}, \theta=60^{\circ}\right)$ is detected in $\mathrm{Cu} / \mathrm{GNR}$ bulks relative to that in $\mathrm{Cu}$ alone $(61.4 \%)$. The presence of a large fraction of HAGBs is conducive to a promoted strain-hardening rate and consequently a higher uniform elongation and failure strain. Specifically, TBs and HAGBs effectively block dislocation glide, thereby forcing the dislocations to tangle and accumulate near these boundaries. However, it is probably easier for slipping dislocations to react with extrinsic dislocations in the low angle 
GBs (LAGBs, $15^{\circ} \geq \theta \geq 2^{\circ}$ ), and this may trigger an easy annihilation of dislocations and a limited dislocation accumulation as in the case of the pure $\mathrm{Cu}$ sample $[38,39]$.

\subsection{Robust electrical transport performance of $\mathrm{Cu} / \mathrm{GNRs}$}

As regards the remarkable electrical conductivity of the $\mathrm{Cu} / \mathrm{GNR}$ system, an existence of additional electron transport pathways is implied in our compound macrostructure, considering that the extra GNDs (Fig. 7a) might predetermine a high electrical resistance according to classical Matthissen's law. This can be rationalized by the local formation of conductive graphitic channels directly onto GNR filaments by generating a strong electric field, which consists of numerous metal-GNR heterostructures with negligible charge loss [56,57]. Additionally, the clean and close interface between metal and quasi-1D parts can minimize interfacial impedance stemming from electron-boundary scattering alongside the internal interfaces. Furthermore, the anisotropic conductance of $\mathrm{Cu} / \mathrm{GNRs}$ is correlated to the orientation of GNR planes, knowing that there is strong anisotropy of the interfacial area resistance between the edge-contacted $\mathrm{Cu}$-graphene interfaces and the surface-contacted interfaces [58]. Further investigation on the intrinsic conducting mechanism at multi-levels using both experimental methods (e.g. conducting AFM measurement) and theoretical calculation and simulation (e.g. density functional theory simulation) are pursued and related works are currently in progress.

\section{Conclusions}

In summary, we present here a strategy for advanced MMC design via integrating and realigning quasi-1D nanoribbon components within a 3D metal environment. This macrostructure of metal-GNR composite system substantially facilitates the utilization of the full advantages of GNRs, namely, their unique dimension, straight and planar geometry, high aspect-ratio and flexibility, superb intrinsic strength and remarkable conductance. As a result 
of these, a co-existence of enhanced strength, ductility, toughness and robust conductance is achieved at the macroscale, which opens up an avenue to effectively address the challenge of strength-ductility and strength-conductance trade-off in artificial materials. When individually, uniformly and intimately incorporated, heterostructuring of quasi-1D, atomic-thin nanomaterials with metal matrices may provide novel opportunities for exploring emergent phenomena and applications by developing designed properties beyond those of homogeneous materials. Moreover, the methodology and concept of configuration optimization are versatile and applicable to other metal-nanophase systems, encompassing various kinds of novel lowdimensional nanofillers (e.g., quantum dots, nanoribbons of $\mathrm{BN}$, phosphorene and $\mathrm{MoS}_{2}$, and so forth [59]) and other metal matrices (e.g., $\mathrm{Al}, \mathrm{Ni}, \mathrm{Ti}, \mathrm{Mg}, \mathrm{Ag}$ ), for the design of nextgeneration MMCs with multifunction and high-performance.

\section{Acknowledgements}

We acknowledge the financial supports of the National Science Fund for Distinguished Young Scholars (No. 51425203), Program of Shanghai Subject Chief Scientist (No. 15XD1501900) and National Basic Research Program of China (No. 2012CB619601).

\section{References}

[1] S.C. Tjong, Recent progress in the development and properties of novel metal matrix nanocomposites reinforced with carbon nanotubes and graphene nanosheets, Mater. Sci. Eng. R, 74 (10) (2013), pp. 281-350.

[2] S.R. Bakshi, D. Lahiri, A. Agarwal, Carbon nanotube reinforced metal matrix composites - a review, Int. Mater. Rev., 55 (1) (2013), pp. 41-64.

[3] A. Nieto, A. Bisht, D. Lahiri, C. Zhang, A. Agarwal, Graphene reinforced metal and ceramic matrix composites: a review, Int. Mater. Rev. (2016), pp. 1-62. 
[4] Z. Niu, W. Ma, J. Li, H. Dong, Y. Ren, D. Zhao, et al., High-strength laminated copper matrix nanocomposites developed from a single-walled carbon nanotube film with continuous reticulate architecture, Adv. Funct. Mater., 22 (24) (2012), pp. 5209-5215.

[5] C. He, N. Zhao, C. Shi, X. Du, J. Li, H. Li, et al., An approach to obtaining homogeneously dispersed carbon nanotubes in $\mathrm{Al}$ powders for preparing reinforced Al-Matrix composites, Adv. Mater., 19 (8) (2007), pp. 1128-1132.

[6] J.G. Park, D.H. Keum, Y.H. Lee, Strengthening mechanisms in carbon nanotubereinforced aluminum composites, Carbon, 95 (2015), pp. 690-698.

[7] B. Chen, K. Kondoh, H. Imai, J. Umeda, M. Takahashi, Simultaneously enhancing strength and ductility of carbon nanotube/aluminum composites by improving bonding conditions, Scr. Mater., 113 (2016), pp. 158-162.

[8] S.J. Yoo, S.H. Han, W.J. Kim, Strength and strain hardening of aluminum matrix composites with randomly dispersed nanometer-length fragmented carbon nanotubes, Scr. Mater., 68 (9) (2013), pp. 711-714.

[9] D. Zhang, Z. Zhan, Strengthening effect of graphene derivatives in copper matrix composites, J. Alloys Compd., 654 (2016), pp. 226-233.

[10] F. Chen, J. Ying, Y. Wang, S. Du, Z. Liu, Q. Huang, Effects of graphene content on the microstructure and properties of copper matrix composites, Carbon, 96 (2016), pp. 836-842.

[11] J. Hwang, T. Yoon, S.H. Jin, J. Lee, T.S. Kim, S.H. Hong, et al.Enhanced mechanical properties of graphene/copper nanocomposites using a molecular-level mixing process, Adv. Mater., 25 (46) (2013), pp. 6724-6729.

[12] Z. Li, Q. Guo, Z. Li, G. Fan, D.B. Xiong, Y. Su, et al., Enhanced mechanical properties of graphene (reduced graphene oxide)/aluminum composites with a bioinspired nanolaminated structure, Nano Lett., 15 (12) (2015), pp. 8077-8083.

[13] J. Wang, Z. Li, G. Fan, H. Pan, Z. Chen, D. ZhangReinforcement with graphene nanosheets in aluminum matrix composites, Scr. Mater., 66 (8) (2012), pp. 594-597.

[14] W.J. Kim, T.J. Lee, S.H. Han, Multi-layer graphene/copper composites: preparation using high-ratio differential speed rolling, microstructure and mechanical properties, Carbon, 69 (2014), pp. 55-65.

[15] S.E. Shin, H.J. Choi, J.H. Shin, D.H. Bae, Strengthening behavior of few-layered graphene/aluminum composites, Carbon, 82 (2015), pp. 143-151.

[16] S.E. Shin, D.H. Bae, Deformation behavior of aluminum alloy matrix composites reinforced with few-layer graphene, Compos. A Appl. Sci. Manuf., 78 (2015), pp. $42-47$.

[17] X. Gao, H. Yue, E. Guo, H. Zhang, X. Lin, L. Yao, et al., Mechanical properties and thermal conductivity of graphene reinforced copper matrix composites, Powder Technol., 301 (2016), pp. 601-607.

[18] R. Jiang, X. Zhou, Z. Liu, Electroless Ni-plated graphene for tensile strength enhancement of copper, Mater. Sci. Eng. A, 679 (2017), pp. 323-328. 
[19] Y. Chen, X. Zhang, E. Liu, C. He, C. Shi, J. Li, et al., Fabrication of in-situ grown graphene reinforced Cu matrix composites, Sci. Rep., 6 (2016), p. 19363.

[20] V. Palermo, I.A. Kinloch, S. Ligi, N.M. Pugno, Nanoscale mechanics of graphene and graphene oxide in composites: a scientific and technological perspective, Adv. Mater., 28 (29) (2016), pp. 6232-6238.

[21] P. Greil, Perspectives of nano-carbon based engineering materials, Adv. Eng. Mater., 17 (2) (2015), pp. 124-137.

[22] S. Cui, I.A. Kinloch, R.J. Young, L. Noé, M. Monthioux, The effect of stress transfer within double-walled carbon nanotubes upon their ability to reinforce composites, Adv. Mater., 21 (35) (2009), pp. 3591-3595.

[23] M. Estili, A. Kawasaki, Engineering strong intergraphene shear resistance in multi-walled carbon nanotubes and dramatic tensile improvements, Adv. Mater., 22 (5) (2010), pp. 607-610.

[24] H. Wang, Z.H. Zhang, Z.Y. Hu, F.C. Wang, S.L. Li, E. Korznikov, et al., Synergistic strengthening effect of nanocrystalline copper reinforced with carbon nanotubes, Sci. Rep., 6 (2016), p. 26258.

[25] K.R. Reddy, B.C. Sin, K.S. Ryu, J. Noh, Y. Lee, In situ self-organization of carbon black-polyaniline composites from nanospheres to nanorods: synthesis, morphology, structure and electrical conductivity, Synth. Met., 159 (19-20) (2009), pp. 1934-1939.

[26] M. Hassan, K.R. Reddy, E. Haque, S.N. Faisal, S. Ghasemi, A.I. Minett, et al., Hierarchical assembly of graphene/polyaniline nanostructures to synthesize free-standing supercapacitor electrode, Compos. Sci. Technol., 98 (2014), pp. 1-8.

[27] K.R. Reddy, B.C. Sin, C.H. Yoo, D. Sohn, Y. Lee, Coating of multiwalled carbon nanotubes with polymer nanospheres through microemulsion polymerization, J. Colloid Interf. Sci., 340 (2) (2009), pp. 160-165.

[28] M. Cakici, R.R. Kakarla, F. Alonso-Marroquin, Advanced electrochemical energy storage supercapacitors based on the flexible carbon fiber fabric-coated with uniform corallike MnO2 structured electrodes, Chem. Eng. J., 309 (2017), pp. 151-158.

[29] M. Terrones, A.R. Botello-Méndez, J. Campos-Delgado, F. López-Urías, Y.I. VegaCantú, F.J. Rodríguez-Macías, et al., Graphene and graphite nanoribbons: morphology, properties, synthesis, defects and applications, Nano Today, 5 (4) (2010), pp. 351-372.

[30] Y. Zhu, D.K. James, J.M. Tour, New routes to graphene, graphene oxide and their related applications, Adv. Mater., 24 (36) (2012), pp. 4924-4955. 
[31] A.L. Higginbotham, D.V. Kosynkin, A. Sinitskii, Z. Sun, J.M. Tour, Lower-defect graphene oxide nanoribbons from multiwalled carbon nanotubes, ACS Nano, 4 (4) (2010), pp. 2059-2069.

[32] S. Cho, K. Kikuchi, A. Kawasaki, On the role of amorphous intergranular and interfacial layers in the thermal conductivity of a multi-walled carbon nanotube-copper matrix composite, Acta. Mater., 60 (2) (2012), pp. 726-736.

[33] S. Cho, K. Kikuchi, T. Miyazaki, A. Kawasaki, Y. Arami, J.F. Silvain, Epitaxial growth of chromium carbide nanostructures on multiwalled carbon nanotubes (MWCNTs) in MWCNT-copper composites, Acta. Mater., 61 (2) (2013), pp. 708-716.

[34] D.V. Kosynkin, A.L. Higginbotham, A. Sinitskii, J.R. Lomeda, A. Dimiev, B.K. Price, et al., Longitudinal unzipping of carbon nanotubes to form graphene nanoribbons, Nature, 458 (7240) (2009), pp. 872-876.

[35] M. Yang, L. Hu, X. Tang, H. Zhang, H. Zhu, T. Fan, et al., Longitudinal splitting versus sequential unzipping of thick-walled carbon nanotubes: towards controllable synthesis of highquality graphitic nanoribbons, Carbon, 110 (2016), pp. 480-489.

[36] Y. Fan, W. Jiang, A. Kawasaki, Highly conductive few-layer Graphene/A12O3 nanocomposites with tunable charge carrier type, Adv. Funct. Mater., 22 (18) (2012), pp. 3882-3889.

[37] D. Lin, C. Richard Liu, G.J. Cheng, Single-layer graphene oxide reinforced metal matrix composites by laser sintering: microstructure and mechanical property enhancement, Acta. Mater., 80 (2014), pp. 183-193.

[38] Y.H. Zhao, J.F. Bingert, X.Z. Liao, B.Z. Cui, K. Han, A.V. Sergueeva, et al., Simultaneously increasing the ductility and strength of ultra-fine-grained pure copper, Adv. Mater., 18 (22) (2006), pp. 2949-2953.

[39] Y.H. Zhao, J.F. Bingert, Y.T. Zhu, X.Z. Liao, R.Z. Valiev, Z. Horita, et al., Tougher ultrafine grain $\mathrm{Cu}$ via high-angle grain boundaries and low dislocation density, Appl. Phys. Lett., 92 (8) (2008), p. 081903.

[40] R. Djugum, K. Sharp, The fabrication and performance of $\mathrm{C} / \mathrm{C}$ composites impregnated with TaC filler, Carbon, 115 (2017), pp. 105-115.

[41] Y. Kim, J. Lee, M.S. Yeom, J.W. Shin, H. Kim, Y. Cui, et al., Strengthening effect of single-atomic-layer graphene in metal-graphene nanolayered composites, Nat. Commun., 4 (2013), p. 2114. 
[42] S. Feng, Q. Guo, Z. Li, G. Fan, Z. Li, D.-B. Xiong, et al., Strengthening and toughening mechanisms in graphene-Al nanolaminated composite micro-pillars, Acta. Mater., 125 (2017), pp. 98-108.

[43] G. Liu, G.J. Zhang, F. Jiang, X.D. Ding, Y.J. Sun, J. Sun, et al., Nanostructured highstrength molybdenum alloys with unprecedented tensile ductility, Nat. Mater., 12 (4) (2013), pp. 344-350.

[44] X. Zhang, J. Zhou, H. Song, X. Chen, Y.V. Fedoseeva, A.V. Okotrub, et al., "Butterfly effect" in $\mathrm{CuO} /$ graphene composite nanosheets: a small interfacial adjustment triggers big changes in electronic structure and Li-Ion storage performance, ACS Appl. Mater. Inter., 6 (19) (2014), pp. 17236-17244.

[45] K.T. Kim, S.I. Cha, T. Gemming, J. Eckert, S.H. Hong, The role of interfacial oxygen atoms in the enhanced mechanical properties of carbon-nanotube-reinforced metal matrix nanocomposites, Small, 4 (11) (2008), pp. 1936-1940.

[46] L. Jiang, H. Yang, J.K. Yee, X. Mo, T. Topping, E.J. Lavernia, et al., Toughening of aluminum matrix nanocomposites via spatial arrays of boron carbide spherical nanoparticles, Acta. Mater., 103 (2016), pp. 128-140.

[47] Z. Zhang, T. Topping, Y. Li, R. Vogt, Y. Zhou, C. Haines, et al., Mechanical behavior of ultrafine-grained Al composites reinforced with B4C nanoparticles, Scr. Mater., 65 (8) (2011), pp. 652-655.

[48] Z. Zhang, D. Chen, Consideration of Orowan strengthening effect in particulatereinforced metal matrix nanocomposites: a model for predicting their yield strength, Scr. Mater., 54 (7) (2006), pp. 1321-1326.

[49] A. Fadavi Boostani, S. Yazdani, R. Taherzadeh Mousavian, S. Tahamtan, R. Azari Khosroshahi, D. Wei,et al., Strengthening mechanisms of graphene sheets in aluminium matrix nanocomposites, Mater. Des., 88 (2015), pp. 983-989.

[50] R.J. Young, I.A. Kinloch, L. Gong, K.S. Novoselov, The mechanics of graphene nanocomposites: a review, Compos. Sci. Technol., 72 (12) (2012), pp. 1459-1476.

[51] H. Li, A. Misra, Z. Horita, C.C. Koch, N.A. Mara, P.O. Dickerson, et al., Strong and ductile nanostructured Cu-carbon nanotube composite, Appl. Phys. Lett., 95 (7) (2009), p. 071907.

[52] C.M. Hu, C.M. Lai, X.H. Du, N.J. Ho, J.C. Huang, Enhanced tensile plasticity in ultrafine-grained metallic composite fabricated by friction stir process, Scr. Mater., 59 (11) (2008), pp. 1163-1166. 
[53] A. Pineau, A. Amine Benzerga, T. Pardoen, Failure of metals III: fracture and fatigue of nanostructured metallic materials, Acta. Mater., 107 (2016), pp. 508-544.

[54] L.Y. Chen, J.Q. Xu, H. Choi, M. Pozuelo, X. Ma, S. Bhowmick, et al., Processing and properties of magnesium containing a dense uniform dispersion of nanoparticles, Nature, 528 (7583) (2015), pp. 539-543.

[55] H. Wei, Z. Li, D.-B. Xiong, Z. Tan, G. Fan, Z. Qin, et al., Towards strong and stiff carbon nanotube-reinforced high-strength aluminum alloy composites through a microlaminated architecture design, Scr. Mater., 75 (2014), pp. 30-33.

[56] S.K. Kim, J.Y. Kim, B.C. Jang, M.S. Cho, S.-Y. Choi, J.Y. Lee, et al., Conductive graphitic channel in graphene oxide-based memristive devices, Adv. Funct. Mater., 26 (41) (2016), pp. 7406-7414.

[57] S.K. Kim, J.Y. Kim, S.-Y. Choi, J.Y. Lee, H.Y. Jeong, Direct observation of conducting nanofilaments in graphene-oxide-resistive switching memory, Adv. Funct. Mater., 25 (43) (2015), pp. 6710-6715.

[58] K.H. Khoo, W.S. Leong, J.T. Thong, S.Y. Quek, Origin of contact resistance at ferromagnetic metal-graphene interfaces, ACS Nano, 10 (12) (2016), pp. 11219-11227.

[59] M. Yagmurcukardes, F.M. Peeters, R.T. Senger, H. SahinNanoribbons: from fundamentals to state-of-the-art applications, Appl. Phys. Rev., 3 (4) (2016), p. 041302. 